\title{
Overview of Survival and Related Parameters in Malignancies with Brain Metastasis
}

\author{
Eda ERDiş, ${ }^{1}$ Birsen YÜCEL,, Semiha URVAY, ${ }^{2}$ Alparslan MAYADAĞLI ${ }^{3}$ \\ 'Department of Radiation Oncology, Cumhuriyet University Faculty of Medicine, Sivas-Turkey \\ ${ }^{2}$ Department of Medical Oncology, Cumhuriyet University Faculty of Medicine, Sivas-Turkey \\ ${ }^{3}$ Department of Radiation Oncology, Bezmi Alem University Faculty of Medicine, İstanbul-Turkey
}

\begin{abstract}
OBJECTIVE
Brain metastasis is the most common type of brain tumor. The present study is an investigation of prognostic factors for survival in patients with brain metastasis.

\section{METHODS}

We retrospectively investigated patients with brain metastasis who were treated at the Cumhuriyet University center for radiation oncology between 2006 and 2014.

RESULTS

The data of 277 patients were analyzed. Age of the patient, performance status, length of time to metastasis, site of primary disease, and performance of metastasectomy were determined to be factors that affect prognosis. Independent prognostic factors were found to be: time to metastasis (hazard ratio [HR]: 0.72; 95\% confidence interval [CI]: 0.52-0.99; $\mathrm{p}=0.0047$ ), performance status (HR: 1.40; 95\% CI: 1.07-1.85; $\mathrm{p}=0.015$ ), and metastasectomy (HR: 0.54; 95\% CI: 0.33-0.89; $\mathrm{p}=0.017$ ).
\end{abstract}

\section{CONCLUSION}

Survival rate was better in patients with breast cancer, longer time before metastasis, good performance, and those who had undergone metastasectomy. Therapeutic approaches should be planned with consideration that patients exhibiting these characteristics might have more favorable therapeutic outcomes.

Keywords: Brain metastasis; metastasectomy; prognostic factors.

Copyright $\odot$ 2016, Turkish Society for Radiation Oncology

\section{Introduction}

Metastatic brain tumors are seen more often than primary brain tumors in cancer cases, and the rate of brain involvement ranges between $20 \%$ and $40 \%$ in cases of malignancy.[1-5] The brain is most commonly invaded in patients with lung or breast cancer, which account for $50 \%$ and $15-20 \%$ of metastatic brain tumors, respectively. Survival remains poor in patients with brain metastasis, and various prognostic scales can be used to make decisions about treatment. [6-9] However, the optimal treatment of brain metastasis is a matter of debate, and many factors can affect the outcome, with each treatment modality having both risks and benefits. [10] Whole-brain irradiation, surgery, and radiosurgery are common modalities for the treatment of brain tumors, and each are recommended by several 
guidelines.[11-13] Overall, local control of the primary disease, and the number, site, and size of the metastasis in the brain must be taken into consideration in the prognostic and therapeutic approaches.

Although current advances in visualization techniques have, in parallel, led to earlier diagnoses and better local treatments of cancer, patient survival is still an important problem. However, the quality of life and survival of the patients have improved, to some extent, with improvements in oncological treatments.[14]

In this study, we investigated the clinical and demographic prognostic factors that affect the survival of cancer patients with brain metastasis. In addition, we aimed to identify any possible independent predictors related to overall survival.

\section{Materials and Methods}

For this research, we retrospectively investigated the data of 285 patients with brain metastasis who had been treated in the Radiation Oncology Clinic in the School of Medicine at Cumhuriyet University between 2006 and 2014. The demographic, clinical, and histopathological data of the patients, including the age, gender, metastasis, comorbidity, Eastern Cooperative Oncology Group (ECOG) performance status, metastatic organ, second series of irradiation, and history of metastasectomy, were obtained from the patient files and hospital records. Telephone calls were made to determine if the patients were still alive, and these data were also recorded. A total of 8 patients were excluded from the study; of these, 7 had multiple metastases and uncontrolled extracranial metastases, while one had no available data. The performance status was evaluated using the ECOG scoring system.

The statistical analysis was performed using the SPSS statistical software (version 15.0), and the rate of survival was calculated using the Kaplan-Meier analysis. The duration of overall survival covered the time from the date of the diagnosis of brain metastasis until death or the date of the last control. Moreover, a multivariate analysis (Cox Regression Analysis) was performed to evaluate the independent factors that affect survival. Those variables found to be significant in the univariate analysis were evaluated using the multivariate analysis, and a p value of less than 0.05 was considered to be statistically significant. Consent from the Cumhuriyet University School of Medicine Ethical Committee was received prior to the study, with regard to collecting, evaluating, analyzing, and interpreting the data.

\section{Results}

For this study, we investigated a total of 277 patients who presented at our clinic with brain metastasis, including 176 (64\%) males and 101 (36\%) females. The median age of the patients was 59 years old (18-81 years old). The patients were investigated in two groups, those 50 years old or older (220 patients, 79\%) and those younger than 50 years old (57 patients, $21 \%$ ).

The primary diagnoses of the patients were: 162 cases of lung cancer (58\%), 57 cases of breast cancer (21\%), 17 cases of gastrointestinal system cancer $(6 \%)$, 14 cancer patients with unidentified primary sites (5\%), 12 cases of genitourinary system cancer (4\%), 8 cases of gynecological cancer (3\%), and 7 cases of other types of cancer $(3 \%)$.

All of the patients had undergone total cranial irradiation, in which three-dimensional conformal radiotherapy was applied using a Varian DHX Eclipse planning system. The radiotherapy was applied at a dose of $3000 \mathrm{cGy}$, with $300 \mathrm{cGy} /$ day for the total cranial area. Other treatments were also applied for the brain metastasis, with 30 patients (11\%) having undergone metastasectomies. A second series of irradiation was required in 21 patients (8\%), due to progression, and cranial conformal radiotherapy was applied as the second serial irradiation. This protocol was conducted at a total of $2000 \mathrm{cGy}$, with $200 \mathrm{cGy} /$ day for the cranial area. Stereotactic radiosurgery (SRS) was not applied in any of the patients.

Overall, the median survival was determined to be 3 months (1-98 months), the mean duration of survival was $7.6 \pm 0.68$ months, and the median value of the time to metastasis was 11 months (1-119 months).

Based on the univariate analysis, the prognostic factors which affected survival included the site of the primary disease (breast cancer, $\mathrm{p}=0.035$ ), age of the patient ( $<50$ years old vs $\geq 50$ years old, $\mathrm{p}=0.033$ ), performance status of the patient $(\mathrm{p}=0.005)$, history of metastasectomy ( $\mathrm{p}=0.006)$, and time for the development of metastasis ( $\mathrm{p}=0.055)$. However, the gender, comorbidity, metastasis at diagnosis, and second series of radiotherapy (RT) were not determined to affect survival ( $p>0.05)$. Table 1 shows the prognostic factors that affect survival. In addition, the survival curves with regard to primary disease are demonstrated in Figure 1, with regard to the ECOG performance status in Figure 2 , and with regard to the application of metastasectomy in Figure 3.

Those independent prognostic factors which positively affect survival were found to be: a favorable 


\begin{tabular}{|c|c|c|c|c|}
\hline \multirow[t]{2}{*}{ Prognostic factors } & \multicolumn{2}{|c|}{$\begin{array}{c}\text { Number of } \\
\text { patients (\%) }\end{array}$} & \multirow[t]{2}{*}{$\begin{array}{l}\text { Median } \\
\text { survival' }\end{array}$} & \multirow[t]{2}{*}{$\mathbf{P}$} \\
\hline & $\mathbf{n}$ & $\%$ & & \\
\hline \multicolumn{5}{|l|}{ Gender } \\
\hline Female & 101 & 36 & 5 & 0.088 \\
\hline Male & 176 & 64 & 3 & \\
\hline \multicolumn{5}{|l|}{ Age } \\
\hline$<50$ years & 57 & 21 & 7 & 0.033 \\
\hline$\geq 50$ years & 220 & 79 & & \\
\hline \multicolumn{5}{|l|}{ Comorbidity } \\
\hline No & 190 & 69 & 4 & 0.291 \\
\hline Yes & 87 & 31 & 3 & \\
\hline \multicolumn{5}{|l|}{ Primary disease } \\
\hline Lung & 162 & 58 & 3 & 0.035 \\
\hline Breast & 57 & 21 & 7 & \\
\hline Other & 44 & 16 & 2 & \\
\hline Unknown primary origin & 14 & 5 & 3 & \\
\hline \multicolumn{5}{|c|}{ Duration of the metastasis development } \\
\hline$\leq 18$ months & 207 & 75 & 3 & 0.055 \\
\hline$>18$ months & 70 & 25 & 5 & \\
\hline \multicolumn{5}{|l|}{ Metastasis at initial diagnosis } \\
\hline No & & & 4 & 0.763 \\
\hline Yes & & & 3 & \\
\hline \multicolumn{5}{|l|}{ ECOG performance status } \\
\hline ECOG 0-1 & 147 & 58 & 6 & 0.005 \\
\hline ECOG 2-4 & 107 & 42 & 2 & \\
\hline \multicolumn{5}{|l|}{ Number of metastatic sites } \\
\hline Isolated brain metastasis & 112 & 40 & 4 & 0.816 \\
\hline Multiple organ metastasis & 165 & 60 & 3 & \\
\hline \multicolumn{5}{|l|}{ Metastasectomy } \\
\hline No & 247 & 89 & 3 & 0.006 \\
\hline Yes & 30 & 11 & 12 & \\
\hline \multicolumn{5}{|l|}{ Second serial radiotherapy } \\
\hline No & 256 & 92 & 3 & 0.210 \\
\hline Yes & 21 & 8 & 11 & \\
\hline
\end{tabular}

${ }^{1}$ Median Survival: Median survival following the development of metastasis. ECOG: Eastern Cooperative Oncology Group.

ECOG performance status $(\mathrm{HR}=1.40,95 \% \mathrm{CI}=1.07-$ $1.85 ; \mathrm{p}=0.015)$, the application of metastasectomy $(\mathrm{HR}=0.54,95 \% \mathrm{CI}=0.33-0.89 ; \mathrm{p}=0.017)$, and time to metastasis of greater than 18 months ( $\mathrm{HR}=0.72,95 \%$ $\mathrm{CI}=0.52-0.99 ; \mathrm{p}=0.047)$. The independent prognostic factors, as determined via the multivariate analysis, are illustrated in Table 2.

\section{Discussion}

In this retrospective study, we investigated the prognostic factors that affect survival in patients with solid tumors and brain metastasis. In these cases, there is of- ten a poor prognosis and low survival rate if the patient is not treated.[15]

Certain important prognostic factors can be used to assess the therapeutic approach towards patients with brain metastasis. In three studies conducted by the Radiation Therapy Oncology Group (RTOG), a total of 1.200 patients were analyzed to determine the prognostic factors in brain metastasis, by evaluating whole brain radiotherapy with different fraction-dose schedules. In this analysis, the age, performance status, control of the primary tumor, and presence or absence of extracranial metastasis were determined to be important prognostic factors. As a result of the analysis, 


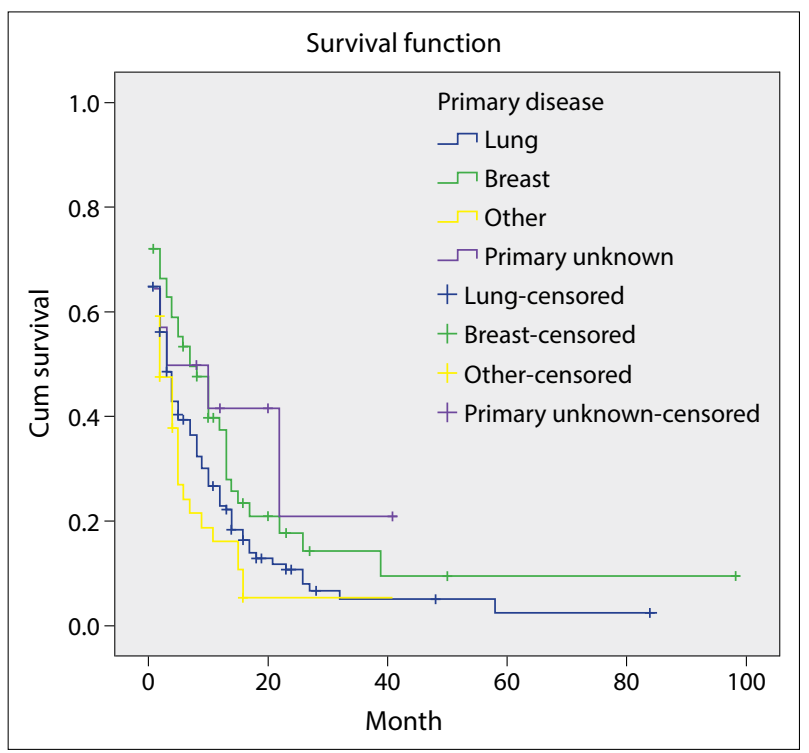

Fig. 1. Survival curves in regard to the primary disease.

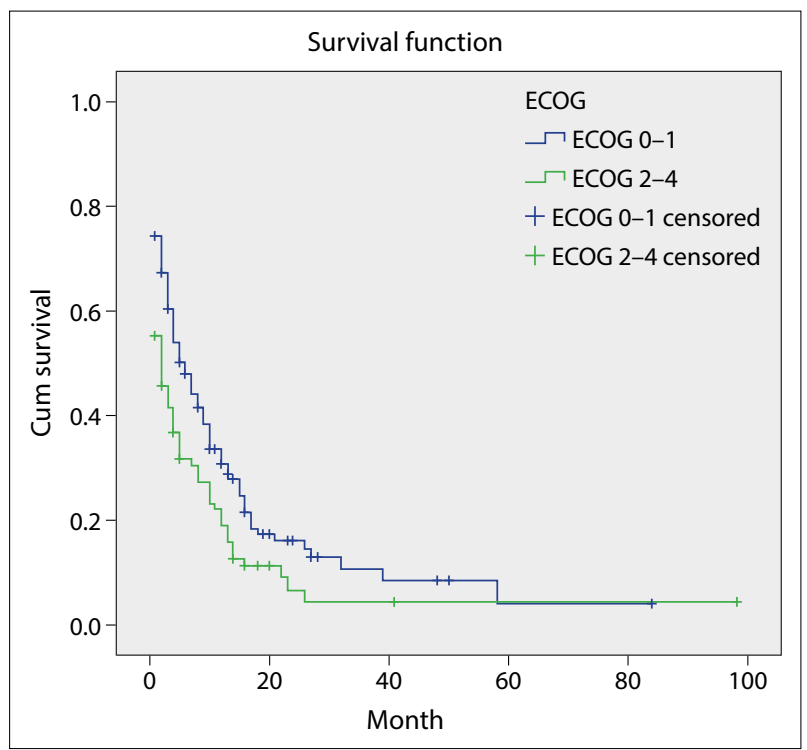

Fig. 2. Survival curves in regard to the ECOG performance status.

three prognostic classes were determined and defined as the recursive partitioning analysis (RPA), including RPA classes I, II, and III:[16,17]

1. Class I: patients younger than 65 years old with brain metastasis only, and with the lower Karnofsky Performance Status (KPS) of 70.

2. Class II: those patients not included in RPA classes I and III.

3. Class III: patients with a KPS of less than 70 .

The best survival was found in RPA class I, with a median value of 7.1 months, while the worst was in

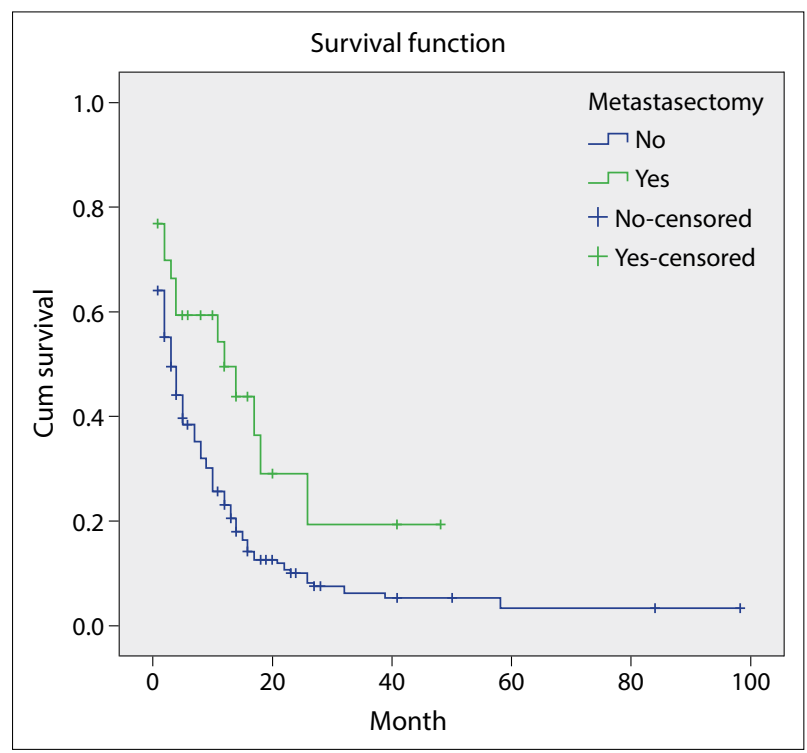

Fig. 3. Survival curves in regard to the application of metastasectomy.

RPA class III, with a median value of 2.3 months. The median value of survival was 4.2 months in RPA class II.[16] In a retrospective study by Nieder et al., including those patients younger than 50 years old with brain metastasis, the prognostic factors that affected survival were the performance status, number of metastases in the brain, presence of extracranial metastasis, gender, and primary disease of the breast.[18] In the same study, the time to metastasis was found to be another factor that affected survival in those patients over 50 years old [18]. In the present study, the survival rate was found to be statistically significantly better in patients younger than 50 years old ( 7 months vs 3 months).

The Eastern Cooperative Oncology Group (ECOG) performance status is used widely in oncology to assess a patient's state of performance. This performance status has been reported in the literature as an efficient and preferable prognostic factor for metastatic tumors. [19] In our study, we determined that those patients with ECOGs from $0-1$ were 1.4-fold more likely to survive than those with ECOGs from 2-4. However, the presence of extracranial metastasis was not found to be statistically significant with regard to survival.

Some studies have reported that the site of the primary tumor is another important prognostic factor that affects overall survival.[18,20] In some of these studies, the rates of survival were reported to be higher in those patients with breast cancer, when compared to other types of cancer.[18,20,21] For example, Nieder et al. performed a study including patients younger than 


\begin{tabular}{|c|c|c|c|c|}
\hline Table 2 & \multicolumn{4}{|c|}{$\begin{array}{l}\text { Multivariate analyses of subgroups (ECOG performance status, metastasectomy } \\
\text { and duration of the metastasis development) }\end{array}$} \\
\hline \multicolumn{2}{|c|}{ Prognostic factors } & Hazard ratio & $95 \% \mathrm{Cl}$ & $\mathbf{p}$ \\
\hline \multicolumn{5}{|c|}{ Duration of the metastasis development } \\
\hline \multicolumn{2}{|c|}{$\leq 18$ months } & 1 & & \\
\hline \multicolumn{2}{|c|}{$>18$ months } & 0.72 & $0.52-0.99$ & 0.047 \\
\hline \multicolumn{5}{|c|}{ ECOG performance status } \\
\hline \multicolumn{2}{|c|}{ ECOG 0-1 } & 1 & & \\
\hline \multicolumn{2}{|c|}{ ECOG 2-4 } & 1.40 & $1.07-1.85$ & 0.015 \\
\hline \multicolumn{5}{|c|}{ Metastasectomy } \\
\hline \multicolumn{2}{|l|}{ No } & 1 & & \\
\hline \multicolumn{2}{|l|}{ Yes } & 0.54 & $0.33-0.89$ & 0.017 \\
\hline
\end{tabular}

ECOG: Eastern Cooperative Oncology Group; Cl: Confidence interval.

50 years old with brain metastasis, and the median survival was 8.5 months in patients with primary breast cancer, but only 6 months in other types of cancer.[18] In the same study, survival was also found to be better in those patients with primary breast cancer who were over 50 years old. However the diagnosis of primary breast cancer was not found to be significant in either age group in the multivariate analysis. Similarly, we determined that the values of median survival were 7 months in patients with breast cancer and brain metastasis, 3 months in lung cancer with brain metastasis, 3 months in brain metastasis with an unidentified primary site, and 2 months in the other metastatic cancer types.

Additional studies in the literature have reported that the time from the initial diagnosis to brain metastasis is closely related with the prognosis.[22] $\mathrm{Du}$ ransoy et al. evaluated the prognostic factors following metastasectomy in 62 patients with brain metastasis, and although it was not statistically significant, better survival was reported in the patients with times to metastasis longer than 12 months ( 10 months vs 6 months).[22] Nieder et al. found the rate of survival to be significantly higher in patients over 50 years old who developed brain metastasis over a period longer than 12 months.[18] In the present study, a survival advantage was present in those patients who developed brain metastasis over periods longer than 18 months. However, the group with the 12-month stratification did not show a survival advantage.

Metastasectomy is another factor which determines a patient's prognosis, and the duration of survival has been reported to be quite long in those patients that underwent metastasectomies.[23,24] Moreover, those cases undergoing surgical treatment had longer dura- tions of survival, which was statistically significant. Early randomized studies have demonstrated that patients with solitary brain metastasis benefit from aggressive local therapy.[25-27] In a serial study by Ferrara et al. that included 100 patients with solitary brain metastasis, the total duration of survival following metastasectomy was found to be 10.2 months.[28] Duransoy et al. have reported the total duration of survival as 9 months, and the median duration of survival as 6 months in 62 patients who underwent metastasectomy. In our study, the median survival time was 12 months in those patients with histories of metastasectomies, but it was 3 months in those who could not undergo metastasectomies. This result suggests that metastasectomy is an independent prognostic factor in patients with brain metastasis.[22]

The application of whole brain irradiation following surgical intervention is still a matter of debate; however, all of our patients underwent cranial radiotherapy following surgery, so we could not make an interpretation of this issue. In the study by Duransoy et al., the duration of survival was 13 months in those patients undergoing post-operative RT, but it was 5 months in those patients who did not undergo post-operative RT $(p<0.001)$. Therefore, we believe that the application of cranial radiotherapy following surgery is a better approach.

\section{Conclusion}

This study revealed that the time to metastasis, history of metastasectomy, and ECOG performance status are factors that affect survival in patients with brain metastasis. However, one must keep in mind that the treatment of brain metastasis must be considered more 
carefully in patients with breast cancer, patients younger than 50 years old, and in those cases of late metastasis and good performance.

\section{Limitations}

This research had some important limitations; for example, it was a retrospective study with a limited amount of data for analysis. Therefore, these findings should be confirmed with prospective controlled randomized trials. The second limitation was related to sample size, since our data was based on a relatively small study population and involved records from a single center. Larger cohort studies would be beneficial in obtaining stronger statistical results. Finally, this research did not include any patients who underwent stereotaxic RT. Therefore, we suggest that further studies which include cases of the same primary disease (e.g. breast cancer), and that also include a sufficient number of cases undergoing metastasectomy and stereotaxic RT would make important contributions to the literature.

\section{Disclosure Statement}

The authors declare no conflicts of interest.

\section{References}

1. Owonikoko TK, Arbiser J, Zelnak A, Shu HK, Shim $\mathrm{H}$, Robin AM, et al. Current approaches to the treatment of metastatic brain tumours. Nat Rev Clin Oncol. 2014;11(4):203,22.

2. Patchell RA. The management of brain metastases. Cancer Treat Rev 2003;29(6):533-40. Crossre

3. Campos S, Davey P, Hird A, Pressnail B, Bilbao J, Aviv $\mathrm{RI}$, et al. Brain metastasis from an unknown primary, or primary brain tumour? A diagnostic dilemma. Curr Oncol 2009;16(1):62-6.

4. Brem S, Panattil JG. An era of rapid advancement: diagnosis and treatment of metastatic brain cancer. Neurosurgery 2005;57(5 Suppl):5-9; discusssion 1-4.

5. Gavrilovic IT, Posner JB. Brain metastases: epidemiology and pathophysiology. J Neurooncol 2008;75(1):514. Crossret

6. Rodrigues G, Bauman G, Palma D, Louie AV, Mocanu J, Senan S, et al. Systematic review of brain metastases prognostic indices. Pract Radiat Oncol 2013;3(2):1016. Crossret

7. Rodrigues G, Gonzalez-Maldonado S, Bauman G, Senan S, Lagerwaard F. A statistical comparison of prognostic index systems for brain metastases af- ter stereotactic radiosurgery or fractionated stereotactic radiation therapy. Clin Oncol (R Coll Radiol) 2013;25(4):227-35. Crossret

8. Yamamoto M, Kawabe T, Higuchi Y, Sato Y, Nariai T, Watanabe $S$, et al. Validity of prognostic grading indices for brain metastasis patients undergoing repeat radiosurgery. World Neurosurg 2014;82:1242-9. Crossree

9. Viani GA, da Silva LG, Stefano EJ. Prognostic indexes for brain metastases: which is the most powerful? Int J Radiat Oncol Biol Phys 2012;83(3):325-30 Crossre

10. Suh JH. Stereotactic radiosurgery for the management of brain metastases. N Engl J Med 2010;362(12):111927. Crossrel

11. Gaspar LE, Mehta MP, Patchell RA, Burri SH, Robinson PD, Morris RE, et al. The role of whole brain radiation therapy in the management of newly diagnosed brain metastases: a systematic review and evidence-based clinical practice guideline. J Neurooncol 2010;96(1):17-32. Crossret

12. Kalkanis SN, Kondziolka D, Gaspar LE, Burri SH, Asher AL, Cobbs CS, et al. The role of surgical resection in the management of newly diagnosed brain metastases: a systematic review and evidence-based clinical practice guideline. J Neurooncol 2010;96(1):33,43.

13. Nieder C, Nestle U, Walter K, Niewald M, Schnabel K. Dose/effect relationships for brain metastases. J Cancer Res Clin Oncol 1998;124(6):346-50. Crossre

14. Barnholtz-Sloan JS, Sloan AE, Davis FG, Vigneau FD, Lai P, Sawaya RE. Incidence proportions of brain metastases in patients diagnosed (1973 to 2001) in the Metropolitan Detroit Cancer Surveillance System. J Clin Oncol 2004;22(14):2865,72.

15. Nussbaum ES, Djalilian HR, Cho KH, Hall WA. Brain metastases. Histology, multiplicity, surgery, and survival. Cancer 1996;78(8):1781-8. Crossre

16. Gaspar L, Scott C, Rotman M, Asbell S, Phillips T, Wasserman $\mathrm{T}$, et al. Recursive partitioning analysis (RPA) of prognostic factors in three Radiation Therapy Oncology Group (RTOG) brain metastases trials. Int J Radiat Oncol Biol Phys 1997;37(4):745-51. Crossre

17. Vivas JP, Sanchez CF, Cedres JM, Montufar SV, Garcia E. Brain metastases, survival and recursive partitioning analysis (RPA) our experience. Reports of Practical Oncology and Radiotherapy 2013;18:89-90. Crossree

18. Nieder C, Grosu AL, Spanne O, Andratschke NH, Geinitz $\mathrm{H}$. Brain metastases in patients under 50 years of age: retrospective analysis. Clin Exp Metastasis 2012;29(8):949-56. Crossre

19. Jang RW, Caraiscos VB, Swami N, Banerjee S, Mak E, Kaya E, et al. Simple prognostic model for patients with advanced cancer based on performance status. J Oncol Pract 2014;10(5):335-41. Crossre 
20. Soffietti R, Cornu P, Delattre JY, Grant R, Graus F, Grisold W, et al. Brain metastases. In: Gilhus NE, Barnes MP, Brainin M (Ed). European Handbook of Neurological Management. 2nd ed. Oxford: Blackwell Publishing Ltd.; 2011. p. 437-45.

21. Hall WA, Djalilian HR, Nussbaum ES, Cho KH. Longterm survival with metastatic cancer to the brain. Med Oncol 2000;17(4):279-86. Crossref

22. Duransoy YK, Selcuki M, Gokce T, Duransoy A. Prognostic Factors in Metastatic Brain Tumors: Study of 62 Patients. J Neurol Sci 2012;29(4):732-43.

23. Bonnette P, Puyo P, Gabriel C, Giudicelli R, Regnard JF, Riquet M, et al. Surgical management of non-small cell lung cancer with synchronous brain metastases. Chest 2001;119(5):1469-75. Crossre

24. Billing PS, Miller DL, Allen MS, Deschamps C, Trastek VF, Pairolero PC. Surgical treatment of primary lung cancer with synchronous brain metastases. J Thorac
Cardiovasc Surg 2001;122(3):548-53. Crossre

25. Patchell RA, Tibbs PA, Walsh JW, Dempsey RJ, Maruyama Y, Kryscio RJ, et al. A randomized trial of surgery in the treatment of single metastases to the brain. N Engl J Med 1990;322(8):494-500. Crossre

26. Patchell RA, Tibbs PA, Regine WF, Dempsey RJ, Mohiuddin M, Kryscio RJ, et al. Postoperative radiotherapy in the treatment of single metastases to the brain: a randomized trial. JAMA 1998;280(17):1485-9. Crossret

27. Vecht CJ, Haaxma-Reiche H, Noordijk EM, Padberg GW, Voormolen JH, Hoekstra FH, et al. Treatment of single brain metastasis: radiotherapy alone or combined with neurosurgery? Ann Neurol 1993;33(6):58390. Crossret

28. Ferrara M, Bizzozzero L, Talamonti G, D’Angelo VA. Surgical treatment of 100 single brain metastases. Analysis of the results. J Neurosurg Sci 1990;34(34):303-8. 